\title{
Limited evidence for main reason for failure of partially excavated and restored teeth
}

\section{Abstracted from \\ Schwendicke F, Meyer-Lueckel H, Dorfer C, Paris S.}

Failure of incompletely excavated teeth - a systematic review. J Dent 2013; 41: 569-580.

Address for correspondence: F. Schwendicke, Department for Conservative Dentistry and Periodontology, Christian-Albrechts-University Kiel, Arnold-Heller Str. 3, 24105 Kiel, Germany. E-mail: schwendicke@konspar.uni-kiel.de

\section{Question: In teeth where incomplete caries excavation is carried out (one- or two-step), what types of failures occur and do certain tooth- or treatment-related factors influence risk of failure?}

Data sources Medline, PubMed, EMBASE and the Cochrane Central Register of Controlled Trials (CENTRAL) were searched between Jan 1967 and Dec 2012. No grey literature searches were carried out.

Study selection Randomised and non-randomised, controlled and uncontrolled, pro- and retrospective clinical studies (in English or German) that investigated one- or two-step incomplete dentinal caries removal (where caries was $>1 / 2$ dentine thickness) were eligible. Studies had to have teeth that were clinically and/or radiologically vital, primary or permanent teeth requiring a restoration but with no pulp exposure.

The main outcomes were; clinical or radiological failure based on reported re-treatment. Failures were classified where possible into pulpal (pain, clinical or radiographic signs of pathology) and non-pulpal (tooth or restoration fracture, restoration loss or breach in integrity, secondary or progressing residual caries or non-pulpal failures),

Data extraction and synthesis Two authors independently reviewed the title and abstract of the articles (without blinding to authors or journals) and both extracted data, with discrepancies resolved through discussion or consultation with a third reviewer. Risk of bias was carried out using Cochrane collaboration guidelines and studies were assessed using GRADE criteria.

Failure was calculated per year and annual failure rates weighted according to the number of teeth. Weighted annual failure rates were then used as the effect estimate for frequency and type of failure. Subgroup analyses were carried out, for factors influencing failure, in studies that compared teeth within one or more of the following groups: primary or permanent teeth; pulpal symptoms prior to treatment; single or multi-surface cavities; one- or two-step incomplete excavation; lining material; and restorative material.

Results Twenty-nine articles reporting 19 trials (12 randomised controlled trials, two controlled trials, five case series \& retrospective studies), with a median follow up of 24 months (IQR; 12 to 48), were included. In 11 studies pulpal complications were the main reason for failure and only two studies found more non-pulpal than pulpal failures. Median annual failure rate was 3.8 (IQR; 1.4 to 4.4 )

From the sub-group analyses, there was significantly lower risk of fail- ure for teeth with one- compared to those with two-step excavation (OR=0.21, 95\% $\mathrm{Cl}[0.08$ to 0.55$]$ ) and for those with single compared with multi-surface lesions $(\mathrm{OR}=0.33,95 \% \mathrm{Cl}$ [0.16 to 0.67$]$. Risk of bias scores varied widely and the quality of the studies was very low. Conclusions Following incomplete removal of deep caries, pulpal failure (pain, clinical or radiographic signs of pathology) was the most common failure type. One-step incomplete excavation for deep caries lesions reduced the risk of failure compared to two-step removal and multisurface lesions had a higher risk of failure than single surface lesions.

\section{Commentary}

In the last decades there has been increasing evidence to support strategies that preserve tooth structure, resulting in caries management evolving from the exclusive domain of techniques based on complete removal of carious tissue prior to tooth restoration, to include a range of conservative approaches, such as sealing of noncavitated caries lesions, ${ }^{1}$ sealing of cavitated lesions ${ }^{2}$ and partial caries removal of deep caries lesions. ${ }^{3}$

The hypothesis behind all these approaches is that sealing of the lesion reduces nutrient availability to the invading bacteria, which ultimately leads to a reduction in bacterial numbers ${ }^{4}$ and lesion arrest.

While there is growing evidence to suggest that partial caries removal is preferable to complete caries removal in deep lesions in symptomless teeth, as a means to reducing the risk of pulp exposure ${ }^{5}$ there are very limited data on best strategies to increase the longitudinal survival of partially excavated and restored teeth. Data, primarily from laboratory studies, ${ }^{6}$ suggest restorations in these teeth may be prone to fractures.

Therefore, clinically determining the reasons for failure (pulpal vs. non-pulpal) of restored teeth that have been partially excavated is a very important question.

A limitation of this study is the combining of one- and two-step partial excavation into a single 'incomplete caries removal group', as soft demineralised dentine is only left purposely after the definite restoration in the one-step procedure. ${ }^{7}$

The majority of included studies (11/19) indicated that partially excavated restored teeth failed most commonly due to pulpal problems. In addition, the review supports findings from other studies that suggest that more failures are associated with a second re-entry to completely remove carious tissue. 
If the survival of the restoration is associated with an adequate seal, it is not surprising that this review found higher failures in situations where achieving a good seal might be more difficult (multi-surface restorations or primary teeth), and when teeth are symptomatic (which might be related to the subjective nature of how we assess pulp status). However, the findings from this review are based on a low level of evidence (limited number of studies, with high risk of bias).

Most of the studies followed restorations for short periods of time, and looking at reasons for restoration replacement was not the main focus. So it is possible, as stated by the authors, that they might be underestimating the non-pulpal problems.

In conclusion, it is difficult based on the limited number and length of existing studies to determine what is the main reason for failure of partially excavated and restored teeth.

This review suggests these teeth might fail more frequently due to pulpal related problems than non-pulpal problems, and that failures may be more frequently associated with situations in which the vitality of the teeth is in question (symptomatic teeth), where sealing the restoration margins might be more difficult (large restorations, or restorations in young children), or where complete caries removal is attempted (two-step excavation).

Margherita Fontana

Department of Cariology and Restorative Sciences, University of Michigan School of Dentistry, Michigan, USA

1. Gooch BF, Griffin SO, Gray SK, et al. Preventing dental caries through school-based sealant programs: updated recommendations and reviews of evidence. I Am Dent Assoc 2009; 140: 1356-1365.

2. Innes NP, Evans D], Stirrups DR. Sealing caries in primary molars: randomized control trial, 5-year results. J Dent Res 2011; 90: 1405-1410.

3. Maltz M, Jardim JJ, Mestrinho HD, Yamaguti PM, Podestá K, Moura MS, de Paula LM. Partial removal of carious dentine: a multicentre randomized controlled trial and 18-month follow-up results. Caries Res 2013; 47: 103-109.

4. Oong EM, Griffin SO, Kohn WG, Gooch BF, Caufield PW. The effect of dental sealants on bacteria levels in caries lesions: a review of the evidence. J Am Dent Assoc 2008; 139: 271-278.

5. Ricketts D, Lamont T, Innes NP, Kidd E, Clarkson JE. Operative caries management in adults and children. Cochrane Database Syst Rev 2013; 3: Art. No: CD003808. DOI: 10.1002/14651858.CD003808.pub3.

6. Hevinga MA, Opdam NJ, Frencken JE, Truin GJ, Huysmans MC. Does incomplete caries removal reduce strength of restored teeth? J Dent Res 2010; 89: 1270-1275.

7. Maltz M, Alves LS. Incomplete caries removal significantly reduces the risk of pulp exposure and post-operative pulpal symptoms. J Evid Based Dent Pract 2013; 13: 120-122.

Evidence-Based Dentistry (2014), 15, 16-17. doi: 10.1038/sj.ebd.6400985 